\title{
Development and Characterization of Mg-SiC Nanocomposite Powders Synthesized by Mechanical Milling
}

\author{
Daniela Penther ${ }^{1} \mathrm{a}^{*}$, Claudia Fleck ${ }^{1}$, Alireza Ghasemi ${ }^{1, c}$, \\ Ralf Riedel $^{2}$ and Sepideh Kamrani ${ }^{1, b}$
}

\author{
${ }^{1}$ Department of Materials Science and Engineering, TU Berlin, 10623 Berlin, Germany \\ 2Department of Materials and Earth Sciences, TU Darmstadt, 64287 Darmstadt, Germany \\ apenther@tu-berlin.de, 'bepideh.kamrani@tu-berlin.de, 'ghasemi@tu-berlin.de
}

Keywords: Magnesium, SiC nanoparticle, powder, nanocomposite, MMC, ball milling.

\begin{abstract}
Magnesium powder in micron scale and various volume fractions of SiC particles with an average diameter of $50 \mathrm{~nm}$ were co-milled by a high energy planetary ball mill for up to $25 \mathrm{~h}$ to produce $\mathrm{Mg}$-SiC nanocomposite powders. The milled $\mathrm{Mg}$-SiC nanocomposite powders were characterized by scanning electron microscopy (SEM) and laser particle size analysis (PSA) to study morphological evolutions. Furthermore, XRD, TEM, EDAX and SEM analyses were performed to investigate the microstructure of the magnesium matrix and distribution of SiCreinforcement. It was shown that with addition of and increase in $\mathrm{SiC}$ nanoparticle content, finer particles with narrower size distribution are obtained after mechanical milling. The morphology of these particles also became more equiaxed at shorter milling times. The microstructural observation revealed that the milling process ensured uniform distribution of $\mathrm{SiC}$ nanoparticles in the magnesium matrix even with a high volume fraction, up to $10 \mathrm{vol} \%$.
\end{abstract}

\section{Introduction}

Magnesium is the lightest engineering metal with a density of $1.74 \mathrm{~g} / \mathrm{cm}^{3}$. Further advantages are its high dimensional stability and superior damping characteristics why it is widely used in the automobile and aviation industries [1,2]. Nevertheless, magnesium has some limitations such as low strength and poor ductility [3]. This is due to its hexagonal closed packed (hcp) structure which provides a limited number of independent slip systems. A way to improve the mechanical properties is to reinforce the magnesium matrix with stronger and stiffer particles like ceramics to create a metal matrix composite (MMC) [4]. Thus, the characteristic properties of metals and ceramics are combined and lead to superior specific properties of the MMCs such as strength, elastic modulus and creep resistance at a low density [5-7]. However, the reinforcement with micron sized ceramic particles usually deteriorates the ductility [8]. Recently, it has been demonstrated that the addition of nanosized reinforcements such as ceramic oxides, $\mathrm{SiC}$ or carbon nanotubes can lead to a simultaneous increase in strength and ductility of magnesium [9-11]. Nanosized reinforcements can withstand deformation without fracturing which overall results in a significant increase in strength and ductility of the composite $[6,12-15]$. However, the function of nanoparticles in a metallic matrix is related to their distribution in the matrix, which can strongly affect the mechanical properties of the composite. Nevertheless, fabrication of nanocomposites is difficult because the uniform dispersion of nanoparticles throughout the metal matrix is still a challenging task. One of the common procedures to fabricate nanocomposites is mechanical milling. This method results in an acceptable distribution of the reinforcing particles without the typical segregation of casted composites [12]. In addition, milling is one of the most effective methods for mechanically reducing grain size and producing nanocrystalline powders.

In the present study, high-energy mechanical milling was used to incorporate $1 \mathrm{vol} \%, 3 \mathrm{vol} \%$ and $10 \mathrm{vol} \% \mathrm{SiC}$ nanoparticles homogeneously in a pure magnesium matrix. The effect of the nanoparticle reinforcement on the morphology and microstructure of milled nanocomposite powders was investigated, as a function of the volume fraction of the reinforcement. 


\section{Experimental Procedure}

Magnesium powder with an average particle size of -325 mesh and two SiC powders, one with an average particle size of $50 \mathrm{~nm}\left(\mathrm{SiC}_{\mathrm{n}}\right)$ and the other with an average particle size of $1 \mu \mathrm{m}\left(\mathrm{SiC}_{\mu}\right)$ were used. All powders have a purity of $99.8 \%$ and were supplied by Alfa Aesar (Ward Hill, MA, USA). Fig. 1 shows the morphology of the as-received magnesium and $\mathrm{SiC}$ nanoparticles.

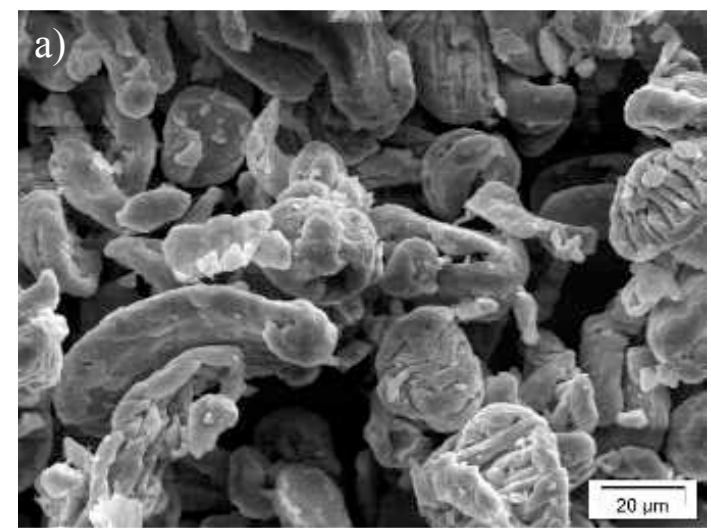

Fig. 1 - Morphology of as-received powders micrograph of SiC nanoparticles.

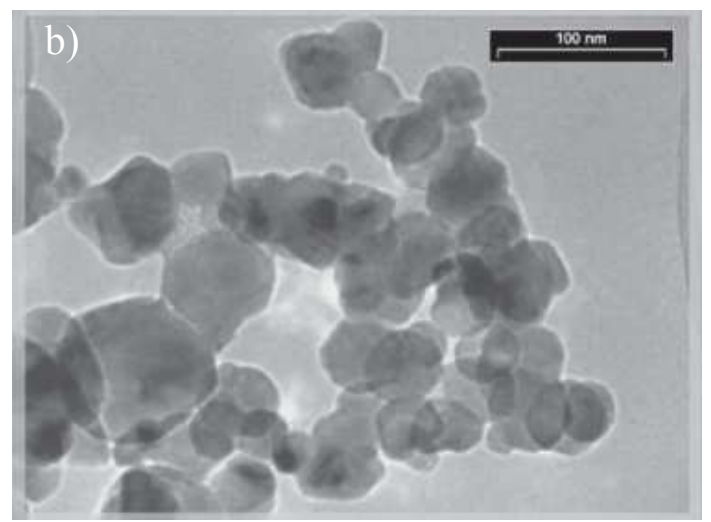

a) SEM micrograph of magnesium and b) TEM

The magnesium powder was mixed with 1 vol\%, 3 vol\% or $10 \mathrm{vol} \%$ of SiC nanoparticles by highenergy mechanical milling. Another powder mixture with 10 vol\% SiC microparticles was prepared for comparison. An overview of the powder mixtures and their naming is given in Table 1. To minimize the cold welding effect, $2 \mathrm{wt} \%$ stearic acid was added to the mixtures as milling process control agent (PCA) [16]. All powder mixtures were blended for $20 \mathrm{~min}$ on a rolling bank. The high-energy mechanical milling was performed in a planetary ball mill (Pulverisette 5, Fritsch, Germany) using zirconia balls in a hard PE vessel for different milling times up to $25 \mathrm{~h}$. The ball-topowder weight ratio (BPR) was 10:1 and a rotational speed of $250 \mathrm{rpm}$ was used. All the handling, mixing, and milling steps were performed under a high purity argon atmosphere in a glove box.

Table 1 - Mechanically milled powder mixtures of magnesium with volume fractions of $0 \mathrm{vol} \%$, $1 \mathrm{vol} \%, 3 \mathrm{vol} \%$ and $10 \mathrm{vol} \% \mathrm{SiC}$ particles and corresponding naming.

\begin{tabular}{cccccc}
\hline & $\mathrm{MM}$ & $\mathrm{M} 1 \mathrm{Sn}$ & $\mathrm{M} 3 \mathrm{Sn}$ & M10Sn & M10S $\mu$ \\
\hline $\mathrm{Mg}[\mathrm{vol} \%]$ & 100 & 99 & 97 & 90 & 90 \\
$\mathrm{SiC}_{\mathrm{n}}[\mathrm{vol} \%]$ & - & 1 & 3 & 10 & - \\
$\mathrm{SiC}_{\mu}[\mathrm{vol} \%]$ & - & - & - & - & 10 \\
\hline
\end{tabular}

After $25 \mathrm{~h}$ of mechanical milling, the milled powders were analyzed by SEM (CamScan Series 2, Obducat, Sweden) in order to study their morphology. Additionally, milled powder particles were embedded in epoxy resin. The microstructure and the distribution of the SiC nanoparticles was investigated on ground and polished sections by high resolution SEM (S-2700, Hitachi Ltd., Japan). Further, transmission electron microscopy (TEM; Tecnai $\mathrm{G}^{2} 20$ S-TWIN, FEI, USA) was used to investigate the microstructure and distribution of the $\mathrm{SiC}$ particles. For this purpose, a lamella was cut out from a powder agglomeration and was thinned to about $100 \mathrm{~nm}$ using the focused ion beam technique.

A high performance laser particle size analyzer (LA-950, Horiba, Japan) with a measuring range from $10 \mathrm{~nm}$ to $3 \mathrm{~mm}$ was used to characterize the particle size and size distribution of the powders after milling. The particles were dispersed in absolute ethanol and ultrasound was applied for 2 min in order to eliminate particle agglomerates. Measurements were made to determine the D50 (median particle size), D90 (the particle size where $90 \%$ of the particles are below that size) and D10 (the particle size where $10 \%$ of the particles are below that size) values of the particles size distribution. 
X-ray diffraction patterns were recorded with the X'Pert Pro from PANalytical (Netherlands) to obtain information about the number and nature of the phases. The width of the diffraction peaks was utilized to determine grain (crystallite) size and the amount of microstrain of the magnesium matrix in the mechanically milled nanocomposite powders.

\section{Results and Discussion}

The morphology of $\mathrm{Mg}-10 \% \mathrm{SiC}$ nanocomposite powders, M10Sn, at different milling times is shown in Fig. 2. At the early stages, the magnesium particles are deformed to a flattened shape with an increase in average size (Fig. 2a, b). Micro-welding between the particles and the onset of fracture were observed at prolonged milling times (Fig. 2c). Due to the welding of the flattened magnesium particles a particle growth started. The powder particles start to break when a sufficient level of defects was generated (Fig. 2d). The fractured particles repeatedly weld together and break again. A steady state condition and formation of equiaxed particles are attained when a balance between welding and fracturing is reached. For a milling time of $25 \mathrm{~h}$, a change in the morphology is found where the particles acquire a more regular and equiaxed shape (Fig. 2e, f). Further, the average size of the particles decreased and a more uniform distribution was reached. The development of the M10Sn powder represents all stages described previously [12,14, 17] such as flattening, welding, fracture and steady state.
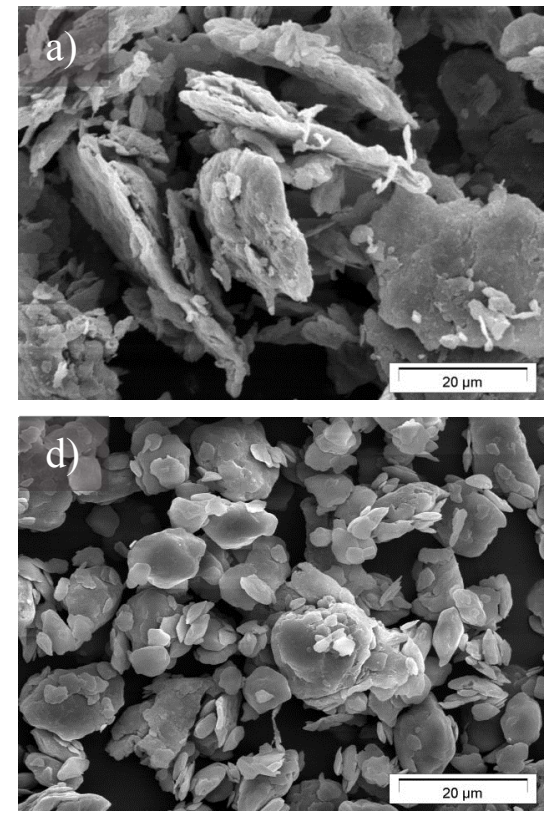
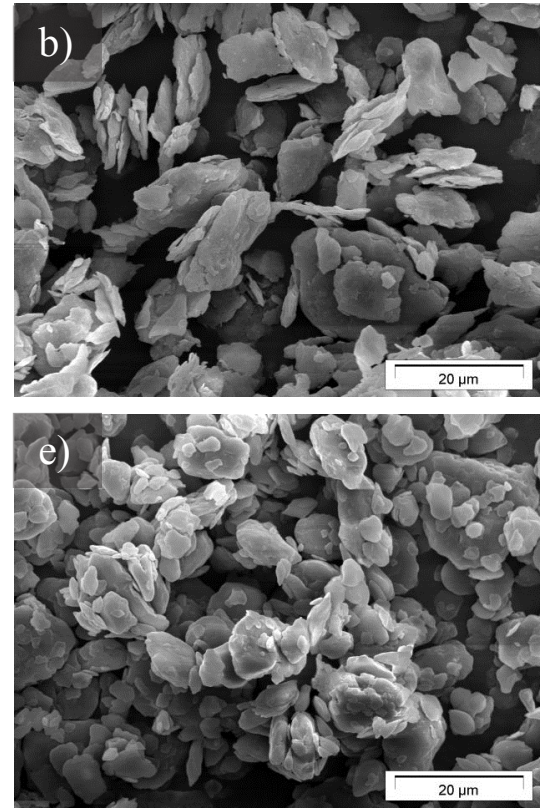
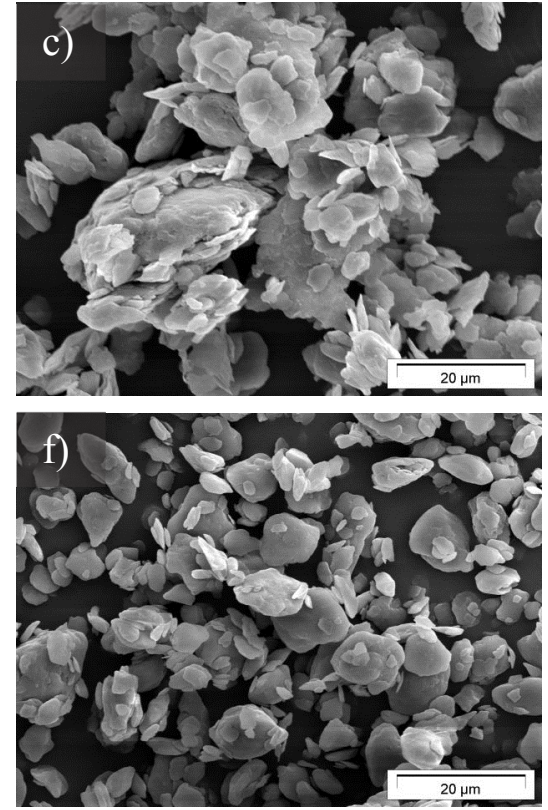

Fig. 2 - Morphology of Mg-10\% SiC composite powder after mechanical milling for a) $1 \mathrm{~h}$, b) $3 \mathrm{~h}$, c) $5 \mathrm{~h}, \mathrm{~d}) 15 \mathrm{~h}, \mathrm{e}) 20 \mathrm{~h}$ and f) $25 \mathrm{~h}$. 

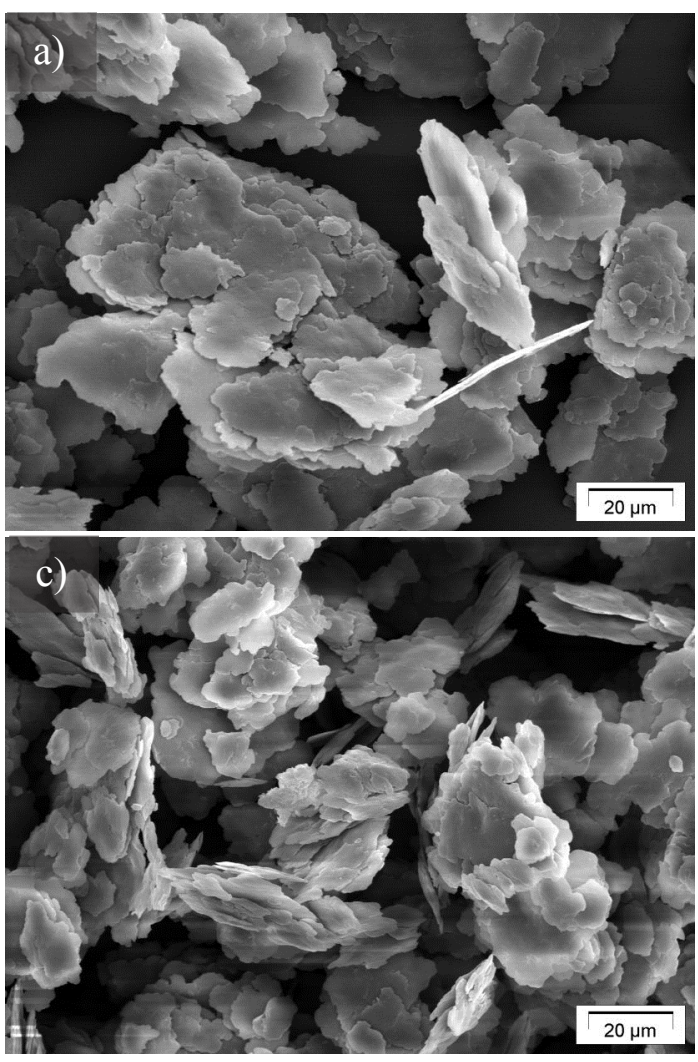
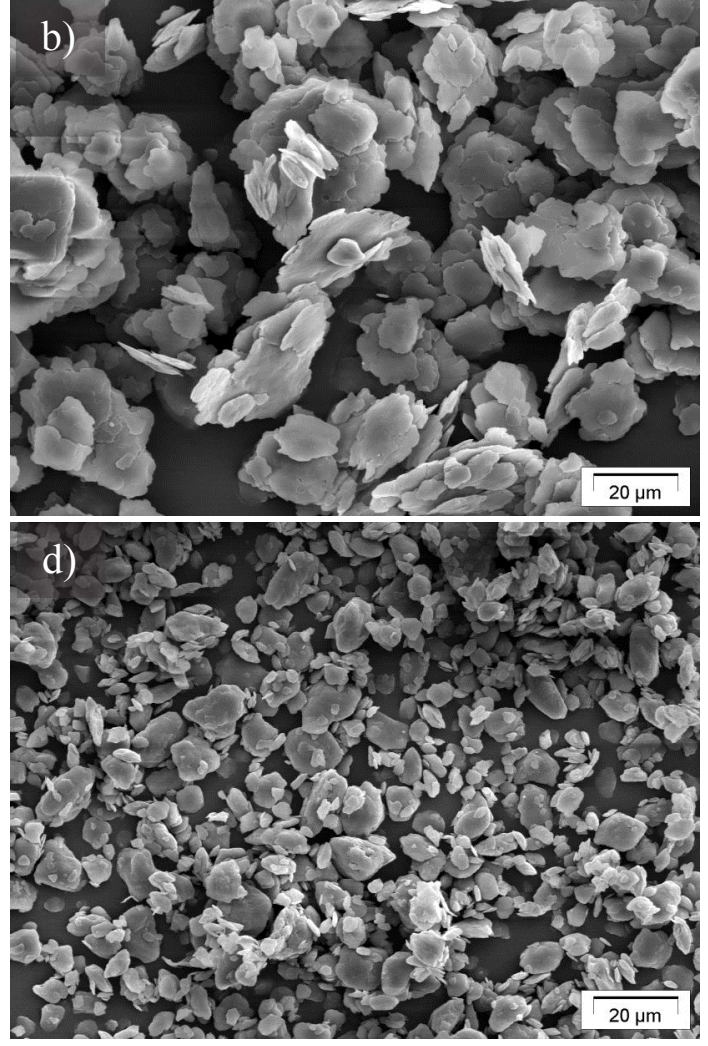

Fig. 3 - Morphology of the milled powders a) MM, b) M1Sn, c) M3Sn and d) M10Sn after $25 \mathrm{~h}$ mechanical milling, showing the decrease in particle size with increasing SiC content.

Besides milling time, the volume fraction of the reinforcing particles shows a significant influence on the powder particle morphology during mechanical milling. Fig. 3 shows the morphology of the MM, M1Sn, M3Sn and M10Sn milled powders after $25 \mathrm{~h}$ of milling. By increasing the SiC content, the particle sizes become finer and more equiaxed after the same milling time. It appears that SiC nanoparticles promote the fracture of the magnesium matrix during mechanical milling. In case of nanoparticles, the high surface to volume ratio increases the local deformation and the rate of work hardening while the fracture toughness decreases. Consequently, the fracture process is enhanced in the presence of nanoparticles which in fact results in the formation of finer particles with a narrow size distribution. Fig. 4 shows the morphology of the M10Sn milled powder in comparison to $\operatorname{M10S} \mu$ after $25 \mathrm{~h}$ of milling. The more equiaxed and finer particles after the same milling time confirms the prominent effect of the $\mathrm{SiC}$ nanoparticles to accelerate the mechanical milling process.
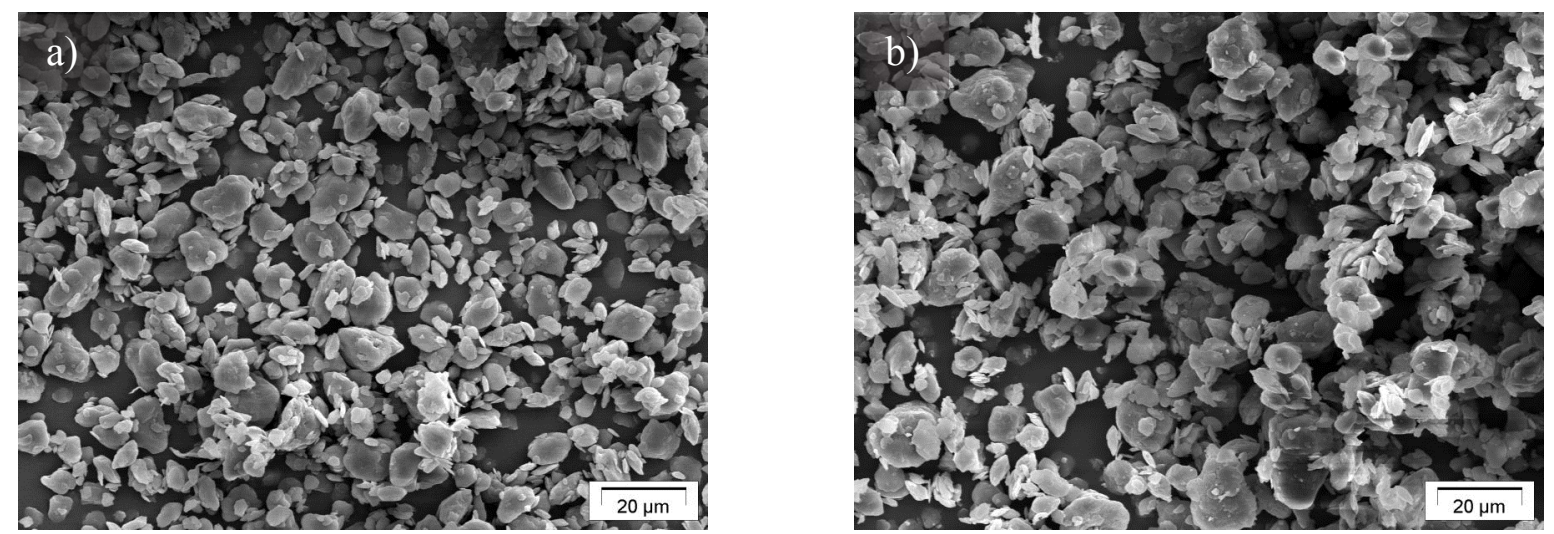

Fig. 4 - Morphology of milled powders a) M10Sn and b) M10S $\mu$ after 25 hours of mechanical milling.

Fig. 5 illustrates the particle size distributions of the MM, M1Sn, M3Sn, M10Sn and M10S $\mu$ milled powders after $25 \mathrm{~h}$ of mechanical milling. All the milled powders exhibit a symmetric log-normal size distribution. The symmetrical gaussian bell-shape indicates also the equilibrium between 
fracture and welding, typical of the final stage of mechanical milling [18]. Furthermore, the results show a reduction in particle size with increasing volume fractions of $\mathrm{SiC}$ nanoparticles, which is in consistency with the SEM observations of the powder morphologies.

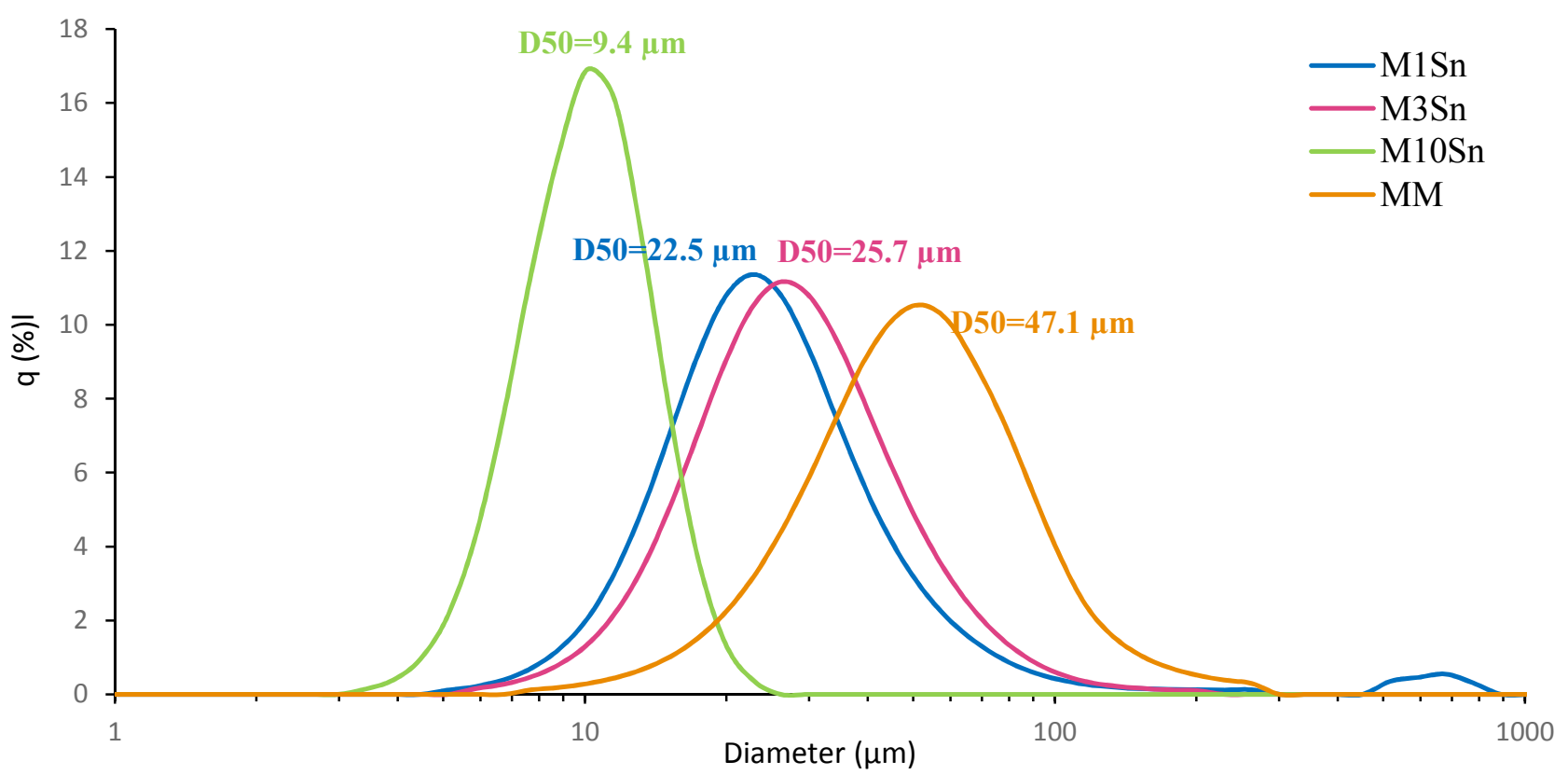

Fig. 5 - Particle size distribution of the milled powders MM, M1Sn, M3Sn and M10Sn.

XRD patterns of the MM, M1Sn, M3Sn and M10Sn powders are shown in Fig. 6a. Besides Mg and $\mathrm{SiC}$, no other phases were detected. Fig. $6 \mathrm{~b}$ shows a magnified view of the (002) reflex of magnesium. With increasing $\mathrm{SiC}$ content, peak broadening is observed while the maximum intensity decreases. As peak broadening represents finer grain sizes and lattice distortion [19], the increase in peak width of magnesium indicates the formation of i) fine crystallite sizes and ii) high density of defects in the magnesium powder with increasing volume fraction of the $\mathrm{SiC}$ nanoparticles.
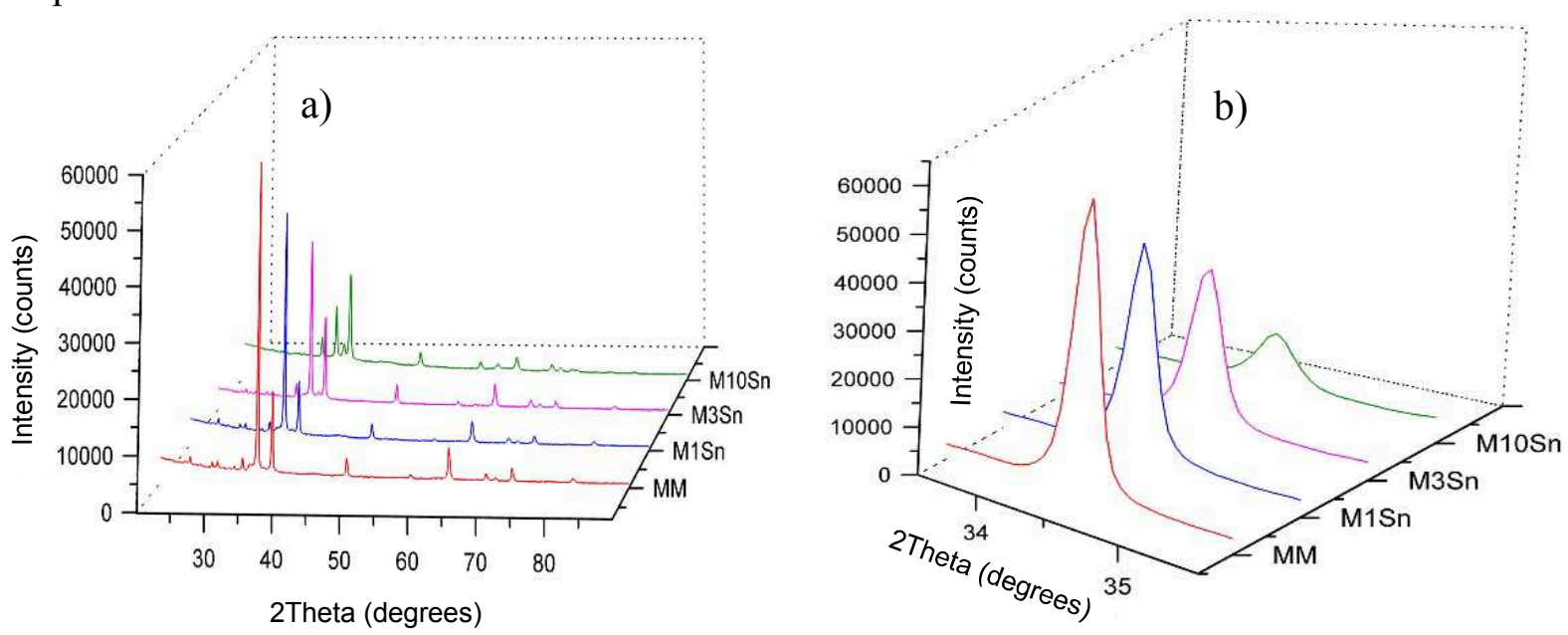

Fig. 6 - XRD patterns of milled powders MM, M1Sn, M3Sn and M10Sn: a) whole pattern, b) magnified view of the (002) Mg peak.

In order to illustrate the distribution of the $\mathrm{SiC}$ nanoparticles in the magnesium nanocomposite powders, cross-sections of M10Sn and M10S $\mu$ milled powders are shown in Fig. 7 where the magnesium matrix appears in light grey and the SiC particles appear as white dots. Although it is known that with higher volume fraction of reinforcement particle a uniform distribution of the nanoparticles is increasingly difficult in comparison to macroparticles, the used mechanical milling setup results in a homogeneous distribution of even $10 \mathrm{vol} \%$ of $\mathrm{SiC}$ nanoparticles in the magnesium matrix [20]. The EDS elemental mapping regarding $\mathrm{Mg}$ and $\mathrm{Si}$ elements in Fig. 8 highlights the uniform distribution of SiC nanoparticles as seen by SEM. 

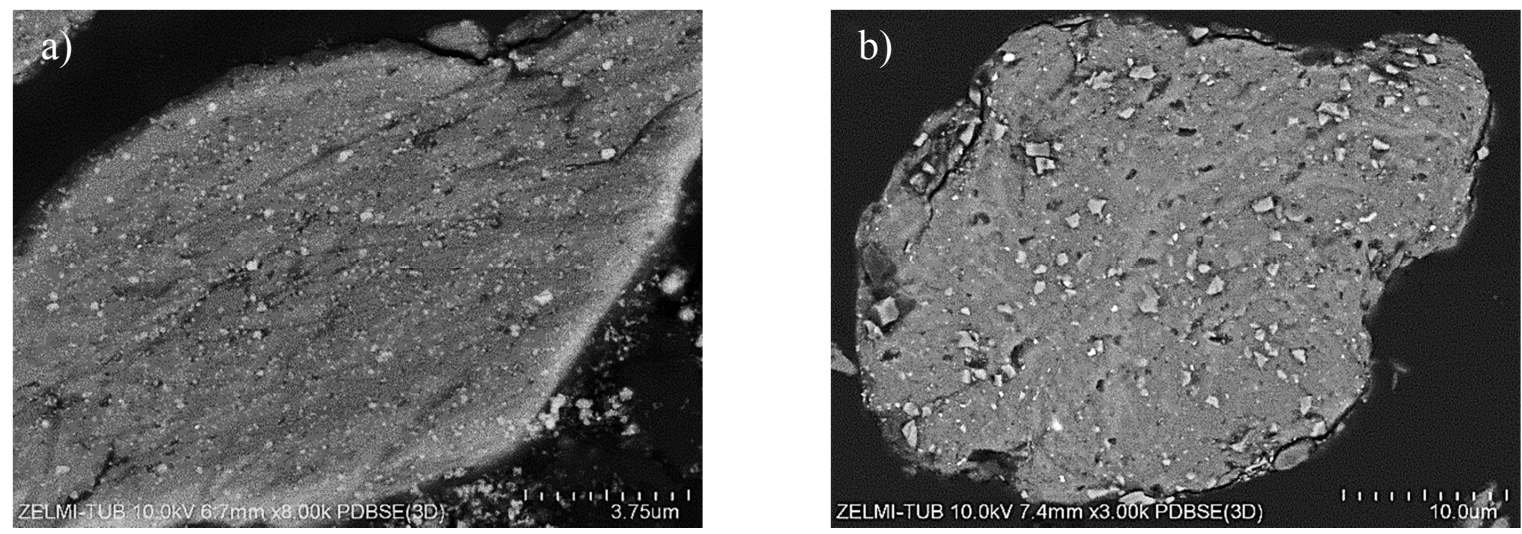

Fig. 7 - Backscattered electron image of a) M10Sn and b) M10S $\mu$ shows a homogeneous distribution of $\mathrm{SiC}$ particles (white) in the magnesium matrix (light grey).
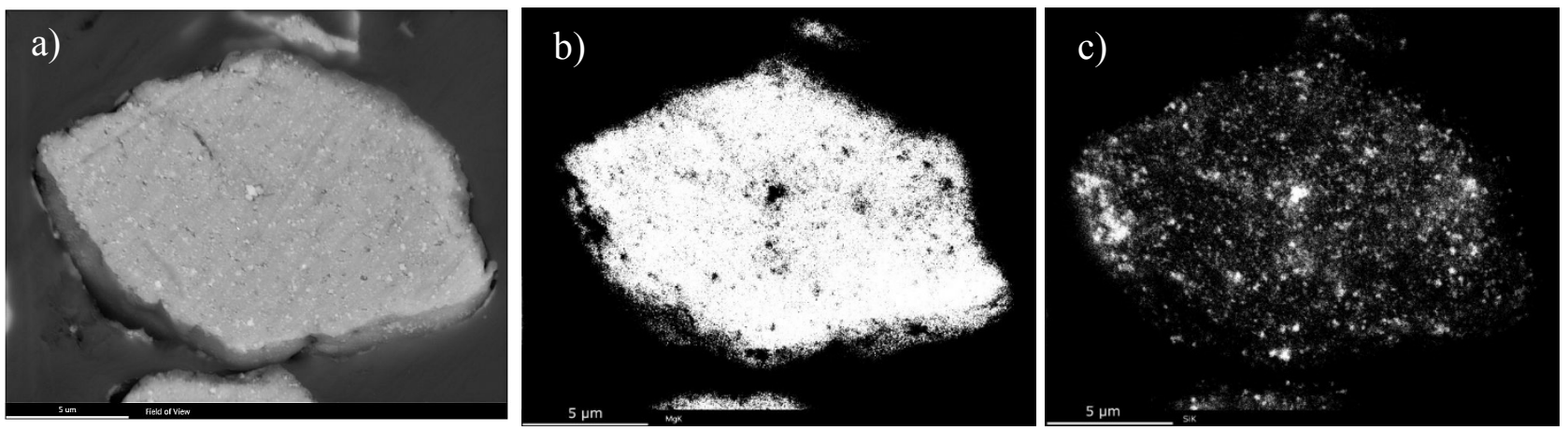

Fig. 8 - Elemental mapping of M10Sn nanocomposite powder: a) SEM micrograph, b) magnesium and c) silicon.

Brightfield TEM micrographs of M10Sn milled powder are shown in Fig. 9. The micrographs not only show the uniform distribution of the $\mathrm{SiC}$ nanoparticles, but they furthermore attest to the development of a nanocrystalline magnesium matrix during the mechanical milling process. The TEM results are thus in good agreement with the XRD peak broadening. Figure $9 \mathrm{~b}$ shows a magnified view of one SiC particle together with the surrounding magnesium matrix. No evidence of the presence of an interfacial product between the $\mathrm{SiC}$ nanoparticle and the magnesium matrix was found, indicating the formation of well-bonded interfaces. A strong interfacial bonding between the $\mathrm{SiC}$ nanoparticles and the nanocrystalline magnesium matrix is promising in terms of superior mechanical properties of the magnesium nanocomposites.
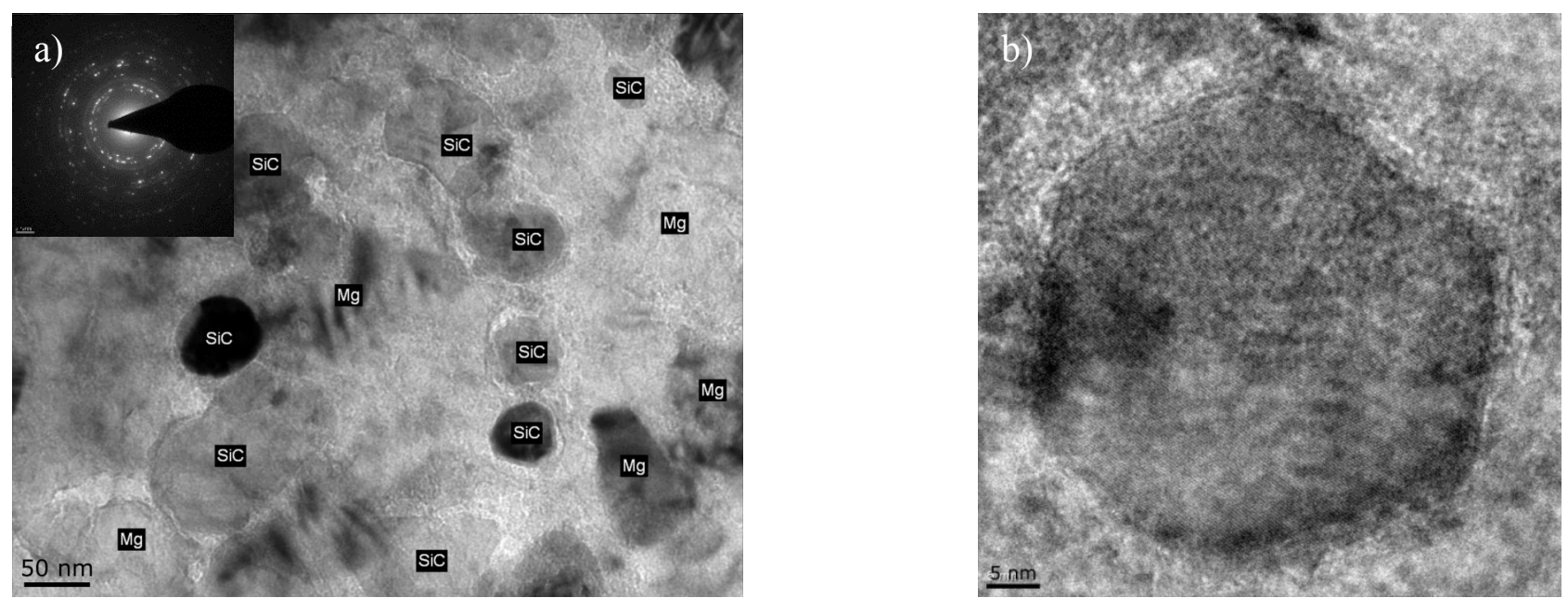

Fig. 9 - Brightfield TEM micrographs of M10Sn nanocomposite powder: a) survey, showing the distribution of $\mathrm{SiC}$ particles within the nanocrystalline $\mathrm{Mg}$ matrix: the compositions of the marked grains were verified by EDS (results not shown); the inset shows the accompanying SAD pattern; $b$ ) magnified view of $\mathrm{SiC}$ particle in $\mathrm{Mg}$ matrix showing a well-bonded interface. 


\section{Summarising Conclusions}

Magnesium powder and $\mathrm{SiC}$ nanoparticles were co-milled to produce $\mathrm{Mg}$-SiC nanocomposite powders. The morphology as well as the microstructure of the milled powders were studied. With higher milling time the particle size of the Mg-SiC powder decreases. In the same duration of milling process, the higher contents of $\mathrm{SiC}$ result in finer particle sizes with more equiaxed morphology. The particle size distribution was in good agreement with the SEM pictures. SEM and TEM analyses verified a homogeneous distribution of $\mathrm{SiC}$ nanoparticles in the magnesium matrix, even with a high volume fraction of $10 \mathrm{vol} \% \mathrm{SiC}$.

\section{Acknowledgement}

The authors gratefully acknowledge the financial support by the DFG (Deutsche Forschungsgemeinschaft) and the members of the group Non-Metallic Inorganic Materials, Institute of Materials Science at TU Darmstadt for providing the ball mill equipment. The authors would also like to thank the Department of Food Technology and Food Material Science for the particle size distribution measurements as well as Ulrich Gernert and Sören Selve at ZELMI for the support during SEM and TEM analyses.

\section{References}

[1] T. M. Pollock, Weight loss with magnesium alloys, Science 328 (2010) 986-7.

[2] A. Luo, J. Renaud, I. Nakatsugawa, J. Plourde, Magnesium castings for automotive applications, JOM 47 (1995) 28-31.

[3] M. K. Habibi, K. S. Tun, M. Gupta, An investigation into the effect of ball milling of reinforcement on the enhanced mechanical response of magnesium, J. Compos. Mater. 45 (2011) 2483-93.

[4] J. Llorca, C. González, Microstructural factors controlling the strength and ductility of particle-reinforced metal-matrix composites, J. Mech. Phy. Solids 46 (1998) 1-28.

[5] I. A. Ibrahim, F. A. Mohamed, E. J. Lavernia, Particulate reinforced metal matrix composites - A review, J. Mater. Sci. 26 (1991) 1137-56.

[6] S. C. Tjong, Novel nanoparticle-reinforced metal matrix composites with enhanced mechanical properties, Adv. Eng. Mater. 9 (2007) 639-52.

[7] M. Manoharan, S. Lim, M. Gupta, Application of a model for the work hardening behavior to $\mathrm{Mg} / \mathrm{SiC}$ composites synthesized using a fluxless casting process, Mater. Sci. Eng., A 333 (2002) 243-9.

[8] H. Z. Ye, X. Y. Liu, Review of recent studies in magnesium matrix composites, J. Mater. Sci. 39 (2004) 6153-71.

[9] C. S. Goh, J. Wei, L. C. Lee, M. Gupta, Development of novel carbon nanotube reinforced magnesium nanocomposites using the powder metallurgy technique, Nanotechnology 17 (2006) 7-12.

[10] C. S. Goh, M. Gupta, J. Wei, L. C. Lee, Characterization of high performance Mg/MgO nanocomposites, J. Compos. Mater. 41 (2007) 2325-35.

[11] M. J. Shen, W. F. Ying, X. J. Wang, M. F. Zhang, K. Wu, Development of high performance magnesium matrix nanocomposites using nano-SiC particulates as reinforcement, J. Mater. Eng. Perform. 24 (2015) 3798-807.

[12] C. Suryanarayana, N. Al-Aqeeli, Mechanically alloyed nanocomposites, Prog. Mater. Sci. 58 (2013) 383-502. 
[13] N. Ramakrishnan, An analytical study on strengthening of particulate reinforced metal matrix composites, Acta Mater. 44 (1996) 69-77.

[14] J. S. Benjamin, Mechanical alloying, Sci. Am. 234 (1976) 40-9.

[15] M. J. Shen, X. J. Wang, T. Ying, K. Wu, W. J. Song, Characteristics and mechanical properties of magnesium matrix composites reinforced with micron/submicron/nano SiC particles, J. Alloys Compd. 686 (2016) 831-40.

[16] C. Machio, H. K. Chikwanda, S. Chikosha, Effect of process control agent (PCA) on the characteristics of mechanically alloyed Ti-Mg powders, SAIMM 111 (2011) 149-53.

[17] C. Suryanarayana, Mechanical alloying and milling, Prog. Mater. Sci. 46 (2001) 1-184.

[18] J. Fogagnolo, F. Velasco, M. Robert, J. Torralba, Effect of mechanical alloying on the morphology, microstructure and properties of aluminium matrix composite powders, Mater. Sci. Eng., A 342 (2003) 131-43.

[19] H.-S. Kim, D.-S. Suhr, G.-H. Kim, D.-W. Kum, Analysis of X-ray diffraction patterns from mechanically alloyed Al-Ti powders, Metals and Materials 2 (1996) 15-21.

[20] K. K. Deng, X. J. Wang, Y. W. Wu, X. S. Hu, K. Wu, W. M. Gan, Effect of particle size on microstructure and mechanical properties of SiCp/AZ91 magnesium matrix composite, Mater. Sci. Eng., A 543 (2012) 158-63. 